\title{
Utilização de resíduos provenientes da construção e demolição de reforma residencial como agregado miúdo para fabricação de concreto
}

The use of construction and residential demolition waste as small aggregate for concrete manufacturing Rayra Ribeiro Monteiro ${ }^{\dagger *}$, Dinah Amaral ${ }^{\dagger}$ Stefani Delgado ${ }^{\dagger}$

Como citar esse artigo. Monteiro, R.R.; Amaral, D.; Delgado, S. Utilização de resíduos provenientes da construção e demolição de reforma residencial como agregado miúdo para fabricação de concreto. Revista Teccen. 2017 Jun./Dez.; 10 (1): XX-XX.

\begin{abstract}
Resumo
A exploração infrene por recursos naturais para aplicação na construção civil é foco de estudos que visam maximizar a reutilização de resíduos que seriam descartados inadequadamente. Dessa maneira, esta pesquisa visa elaborar um concreto utilizando resíduos de construção e demolição como agregado miúdo de forma a obter uma boa aplicabilidade na construção civil. A diversidade de resíduos coletados pode desencadear reações com os demais compostos do concreto, alterando a sua qualidade e consequentemente o resultado final. A aplicabilidade do concreto na construção civil dependerá, dentre outros fatores, da resistência aos esforços de compressão que são analisados em equipamento apropriado. Os resultados apresentaram a possibilidade de inserção do material em estudo em algumas modalidades de concreto, como por exemplo, concreto magro, chaminés, meio-fio, calçadas, artefatos de concreto, desde que atendam aos requisitos das normas vigentes.

Palavras-Chave: Agregado; Concreto; Resíduos; Sustentabilidade.
\end{abstract}

\section{Introdução}

A construção civil possui uma representação importante no consumo de recursos naturais e na geração de impactos ambientais. Com a aproximação de debates sobre desenvolvimento sustentável, este setor deve se adequar, de forma a elaborar projetos voltados para sustentabilidade ambiental, buscando a reutilização de resíduos e redução de desperdício (Angulo, 2000).

A inclusão de práticas de sustentabilidade na engenharia civil é uma tendência progressiva no mercado (Corrêa, 2009). A busca incessante por meios de reduzir, reciclar e reutilizar, são objetos de estudos e pesquisas a fim de promover maneiras de evitar desperdício e, principalmente, reutilizar materiais que seriam descartados na natureza.

O setor da construção civil é o responsável pela geração de 50 a $70 \%$ de todos os resíduos sólidos nas cidades, provenientes de demolições e resíduos de sobra de obra, tornando-se um dos maiores responsáveis pelos impactos ambientais. Estima-se que dentre todos os recursos naturais consumidos pela sociedade, a construção civil representa de 20 a $50 \%$ da totalidade.

Afiliação dos autores: $\uparrow$ Universidade Severino Sombra, Vassouras, RJ, Brasil.

*E-mail para correspondência: rayra.monteiro08@gmail.com 
(Sjöström, 1992 como citado em John, 2001).

O resíduo da construção civil (RCC), habitualmente conhecido como entulho, é todo resto de material como: tijolo, argamassa, concreto, madeira oriundos do desperdício de uma obra. Em contrapartida, os resíduos de demolições são formados apenas por fragmentos, o que enaltece seu potencial qualitativo, comparativamente ao entulho de construção².

O Conselho Nacional de Meio Ambiente (CONAMA), 307 (2002), estabelece critérios para gerir resíduos da construção civil, classificando-os em categorias, e instituindo destinações adequadas às respectivas classes. Os resíduos, objetos desta pesquisa, são qualificados como classe $\mathrm{A}$. Nesta classe estão incluídos os resíduos que são reutilizáveis ou recicláveis como agregados, ou seja, resíduo de construção, demolição, reformas e reparos de pavimentação e edificações; componentes cerâmicos como tijolos, blocos, placas de revestimento; argamassa e concreto.

A reutilização de resíduos como agregado na construção civil além de minimizar impactos ambientais, irá reduzir a extração de areia e pedra de fontes naturais, que antes eram julgados como inesgotáveis (Vieira, Molin, \& Lima, 2004). Grubba (2009) menciona que o resíduo de construção e demolição $(\mathrm{RCD})$ pode ser reciclado na forma de agregados por meio de um beneficiamento, composto de operações de triagem, britagem, peneiramento e armazenamento.

Essa linha de pesquisa vem sendo retratada por diversos autores que buscam o desenvolvimento de novas técnicas de utilização desses resíduos para a construção civil. Segundo Angulo (2000), a aplicação de agregados de RCD é limitada a concretos estruturais e blocos devido à heterogeneidade das suas propriedades. Assim, como afirmam Vieira et al. (2004), essa heterogeneidade de propriedades ocorre pela variação do tipo de obra, das técnicas construtivas, da fase em que se encontra a construção, entre outros fatores. No entanto, estes agregados que antes seriam descartados, podem ser utilizados em situações de menor exigência de qualidade, como na pavimentação.

Cunha,Lacerda \& Delgado(2016) após analisarem diferentes porcentagens de RCD no concreto, mostram que na medida em que se aumenta a quantidade de entulho, há uma redução nos resultados de resistência à compressão.

Com o propósito de minimizar os impactos ambientais e reduzir a extração de areia de recursos naturais, essa pesquisa visa elaborar um concreto utilizando resíduos de construção e demolição da construção civil na composição dos agregados miúdos, possibilitando designar uma provável aplicabilidade para o concreto a partir dos resultados da análise de compressão.

A aplicabilidade do concreto reciclado será identificada após análise de esforço de compressão axial, podendo ser destinado à fabricação de concreto estrutural ou não estrutural de acordo com sua resistência. Para que o concreto possa ser empregado para fins estruturais é imprescindível que a resistência a compressão seja igual ou superior a $20 \mathrm{MPa}$ (NBR 8953 , 2015). O concreto não estrutural fabricado com agregados recicláveis é regulamentado pela NBR 15116 (2004) que estabelece requisitos específicos nas propriedades dos agregados como teor de fragmentos, absorção de água, contaminantes, entre outros.

\section{Material e métodos}

Os materiais empregados para elaboração do concreto foram concedidos pela Universidade Severino Sombra, localizada em Vassouras, Rio de Janeiro,com exceção do RCD. São eles:

-Cimento CPIII Portland;

-Agregado miúdo (areia média lavada constituindo $80 \%$ e RCD $20 \%$ );

- Agregado graúdo (brita $\mathrm{n}^{\circ}$ ));

-Água.

Todos os equipamentos utilizados para fabricação do concreto e análise de compressão, bem como o laboratório foram disponibilizados pela instituição de ensino Universidade Severino Sombra- Vassouras/RJ. São eles:

-Peneira $(2,18 \mathrm{~mm})$

-Padiola (20x32x32 cm);

-Betoneira;

-Forma cilíndrica de PVC de $10 \mathrm{~cm}$ de diâmetro e $20 \mathrm{~cm}$ de altura (corpo de prova);

-Máquina de abatimento (contador de golpes);

- Colher de pedreiro;

-Prensa hidráulica

O processo para obtenção de resistência a compressão do concreto envolve etapas de produção e cura, perfazendo-se após submeter o material analisado na prensa hidráulica, que apresenta o resultado do esforço de compressão do material em estudo.

\section{demolição}

Coleta dos resíduos de construção e

Os resíduos de construção e demolição foram coletados em uma reforma residencial em alvenaria na cidade de Vassouras/ RJ, classificados como classe A, pelo CONAMA 307 (2002). O material foi coletado aleatoriamente incluindo fragmentos de vidro, pedra, areia, pedaços de tijolo, azulejo, ou seja, uma composição heterogênea com materiais de diferentes características. Estes resíduos, de forma geral, eram de pequenas dimensões, e por isso foram inseridas na composição do agregado miúdo, não podendo ser substituída pelo agregado graúdo devido à diferença de tamanho. Os rejeitos foram fragmentados até que tivessem 


\section{granulometria similar à da areia, e posteriormente foram peneirados conforme a Figura 1.}

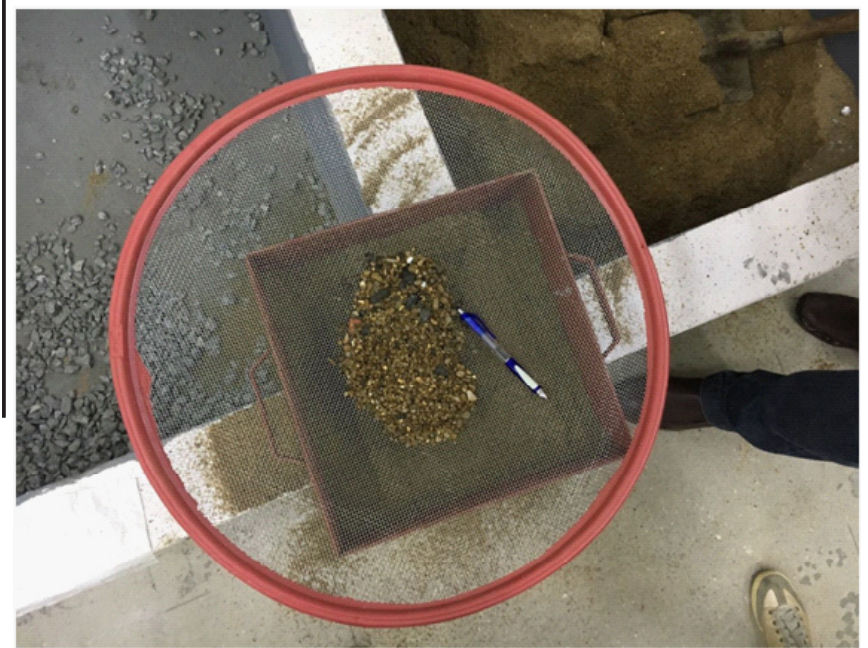

Figura 1: RCD após coleta e fragmentação, passando pelo peneiramento. Autoria própria.

\section{Definição do Traço}

Essa etapa define as quantidades expressas de cada componente do concreto, sendo estabelecida a seguinte relação de cimento, areia e brita: 1:1:2 (respectivamente). Considerando o estudo de Cunha et al. (2016), que relata que a inserção de RCD como agregado afeta o valor da resistência final do concreto, foi estabelecido a dosagem 1:1:2 representado pela tabela de Caldas Branco como o valor máximo de resistência a compressão (40 $\mathrm{MPa})$. A quantidade de cada elemento está apresentada no Quadro 1.

Quadro 1: Quantidade dos materiais utilizados na confecção do concreto.

\begin{tabular}{|c|c|}
\hline Material & Quantidade $\left(\mathrm{m}^{3}\right)$ \\
\hline Brita & 0,02048 \\
\hline Água & 0,00512 \\
\hline Areia & 0,008192 \\
\hline RCD & 0,002048 \\
\hline Cimento & 0,01024 \\
\hline
\end{tabular}

\section{Fator água cimento}

Segundo Mehta \& Monteiro (2008) o teor de água pasta de cimento tem influência direta nas propriedades do concreto, como: trabalhabilidade, permeabilidade, porosidade, resistência à compressão e durabilidade. A quantidade de água empregada atua sobre a resistência à segregação e manutenção da homogeneidade da mistura, durante manuseio e vibração. A trabalhabilidade é uma propriedade transitória que depende de diversos fatores, dentre os quais se destacam: as características e dosagens dos materiais constituintes e o modo de produção do concreto. Quanto maior o fator água/cimento, maior a trabalhabilidade da mistura. A resistência da pasta (mistura de água e cimento como aglomerante) é o fator de principal influência na resistência à compressão do concreto. Quando se aumenta o fator água cimento, a resistência diminui. O primeiro a conhecer esta relação de dependência foi Abrams, em 1919. Ele demonstrou experimentalmente que o fator água/ cimento determinava a resistência do concreto, o qual dependia das propriedades da pasta endurecida. Diante disso, o fator água/cimento do projeto experimental foi fixado na proporção de 0,5 para que se conheça apenas a influência dos resíduos aproveitados (principal objeto de estudo) como agregados e não haja interferência na resistência devido às variações na dosagem do fator água/cimento, não o tornando mais uma variável do projeto.

\section{Mistura dos componentes}

A produção do concreto ocorreu de forma similar ao concreto convencional. Com a betoneira em funcionamento, os materiais foram adicionados (com auxílio da padiola) na seguinte ordem: brita, água, areia e RCD, e por último o cimento.

Os materiais foram misturados até formar uma massa homogênea, conforme recomenda a NBR 12655 (2015).

\section{Moldagem}

Imediatamente após a homogeneização da massa na betoneira, o concreto foi disposto em 12 corpos de prova cilíndricos conforme mostra a Figura 2. O adensamento do concreto foi realizado em duas camadas, mecanicamente, com 12 golpes (NBR 5738, 2003), através da máquina de abatimento.

Após adensar a segunda camada, foi realizado o rasamento da superfície da borda com o molde, empregando uma colher de pedreiro para esta finalidade (NBR 5738, 2003).

\section{Cura}

Após a moldagem, os corpos de prova foram colocados sobre uma superfície lisa, livre de vibrações e protegida de intempéries, onde permaneceram por sete dias, quando foram desmoldados.

\section{Ensaio de compressão}

Os corpos de prova foram ensaiados na prensa hidráulica conforme a Figura 3, conforme a NBR 6118 (2003) os ensaios de compressão deverão ser realizados em dias distintos sendo um deles necessariamente aos 28 dias, com base nisso os ensaios foram feitos com as seguintesidades do concreto: 7 dias, 14 dias, 21 dias e 28 dias. Para cada idade a ser rompida, foram 
reservados três corpos de prova para contemplar um desvio padrão.

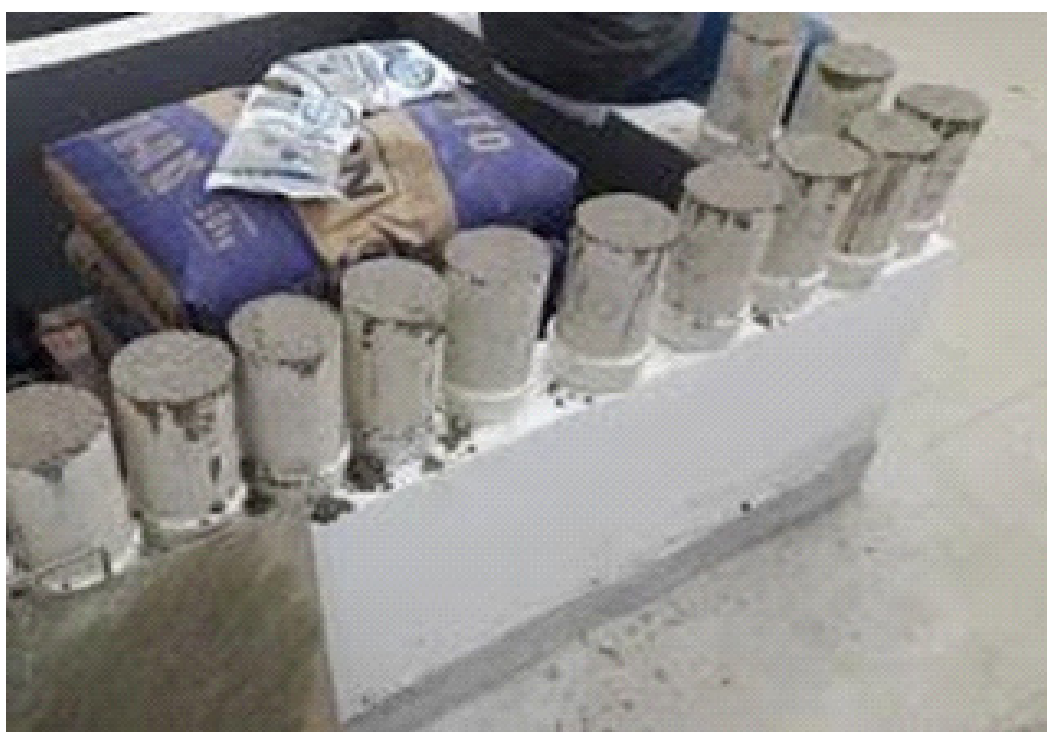

Figura 2: Corpos de prova cilíndricos durante a moldagem. Autoria própria.

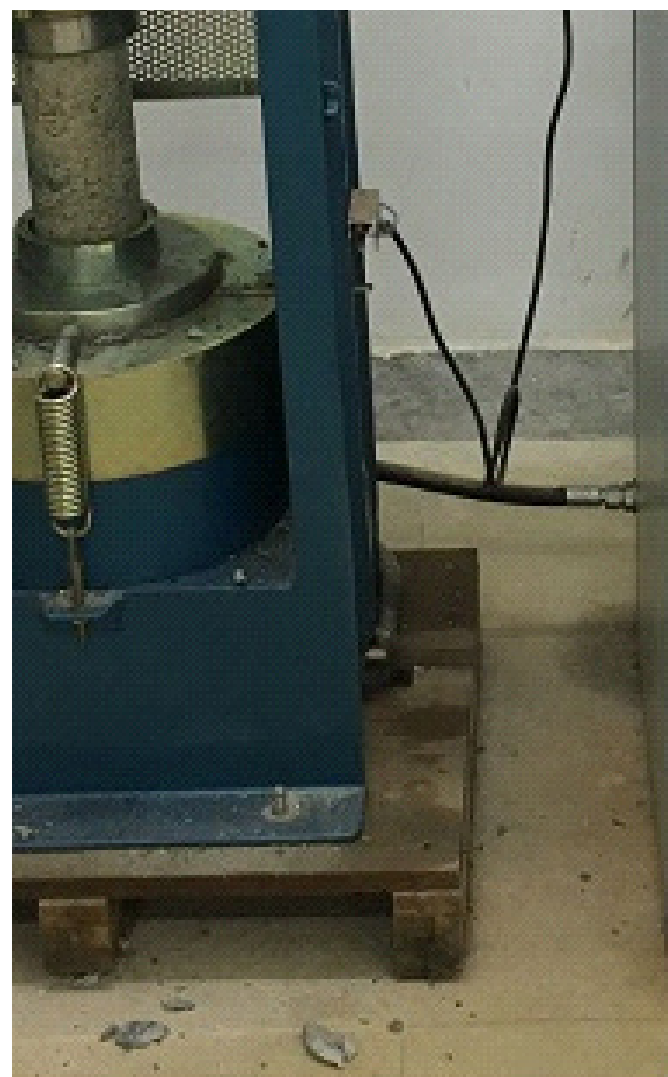

Figura 2: Ensaio de compressão axial do concreto na prensa hidráulica. Autoria própria.

\section{Resultados e discussões}

Os valores de resistência à compressão do concreto estão apresentados nos Quadros 2, 3, 4, 5.

Ao analisar os dados, verifica-se o aumento da resistência à compressão dos corpos de prova, na medida em que se aumentam os dias de cura para o rompimento, conforme mostra o gráfico na Figura 4. Entretanto, passados 28 dias, não se obteve a resistência necessária para fins estruturais. As prováveis causas pela baixa resistência a compressão do concreto, verifica-se que os agregados utilizados constituíam um composto heterogêneo com diferentes características e propriedades. Tal circunstância pode ter contribuído para que estabelecesse a reação álcali-agregado, um processo que ocorre no concreto endurecido e que se desenvolve devido à combinação de três agentes: álcalis do cimento, agregado reativo ou potencialmente reativo e a presença constante de umidade. (Lima, Silva \&Costa, n.d.). Assim, entende-se que essa reação contribui 
Quadro 2: Valores de resistência à compressão em 7 dias de cura.

\begin{tabular}{|c|c|}
\hline \multicolumn{2}{|c|}{7 DIAS DE CURA } \\
\hline $\mathbf{1}^{\mathbf{0}}$ Corpo de Prova & $5,55 \mathrm{MPa}$ \\
\hline $\mathbf{2}^{\mathbf{o}}$ Corpo de Prova & $5,87 \mathrm{MPa}$ \\
\hline $\mathbf{3}^{\mathbf{0}}$ Corpo de Prova & $6,04 \mathrm{MPa}$ \\
\hline Média & $5,82 \mathrm{MPa}$ \\
\hline Desvio Padrão & $0,2031418 \mathrm{MPa}$ \\
\hline
\end{tabular}

Quadro 3: Valores de resistência à compressão em 14 dias de cura

\begin{tabular}{|c|c|}
\hline \multicolumn{2}{|c|}{ 14 DIAS DE CURA } \\
\hline $\mathbf{1}^{\circ}$ Corpo de Prova & $8,30 \mathrm{MPa}$ \\
\hline $\mathbf{2}^{\mathbf{0}}$ Corpo de Prova & $8,31 \mathrm{MPa}$ \\
\hline $\mathbf{3}^{\circ}$ Corpo de Prova & $8,30 \mathrm{MPa}$ \\
\hline Média & $8,30 \mathrm{MPa}$ \\
\hline Desvio Padrão & $0,0057706 \mathrm{MPa}$ \\
\hline
\end{tabular}

Quadro 4: Valores de resistência à compressão em 21 dias de cura.

\begin{tabular}{|c|c|}
\hline \multicolumn{2}{|c|}{21 DIAS DE CURA } \\
\hline $\mathbf{1}^{\mathbf{0}}$ Corpo de Prova & $8,41 \mathrm{MPa}$ \\
\hline $\mathbf{2}^{\mathbf{0}}$ Corpo de Prova & $9,36 \mathrm{MPa}$ \\
\hline $\mathbf{3}^{\mathbf{0}}$ Corpo de Prova & $9,36 \mathrm{MPa}$ \\
\hline Média & $9,04 \mathrm{MPa}$ \\
\hline Desvio Padrão & $0,4478466 \mathrm{MPa}$ \\
\hline
\end{tabular}

Quadro 5: Valores de resistência à compressão em 28 dias de cura

\begin{tabular}{|c|c|}
\hline \multicolumn{2}{|c|}{28 DIAS DE CURA } \\
\hline $\mathbf{1}^{\mathbf{0}}$ Corpo de Prova & $9,73 \mathrm{MPa}$ \\
\hline $\mathbf{2}^{\mathbf{0}}$ Corpo de Prova & $9,4 \mathrm{MPa}$ \\
\hline $\mathbf{3}^{\circ}$ Corpo de Prova & $10,6 \mathrm{MPa}$ \\
\hline Média & $9,91 \mathrm{MPa}$ \\
\hline Desvio Padrão & $0,506162 \mathrm{MPa}$ \\
\hline
\end{tabular}

\section{Resistência à Compressão (MPa)}

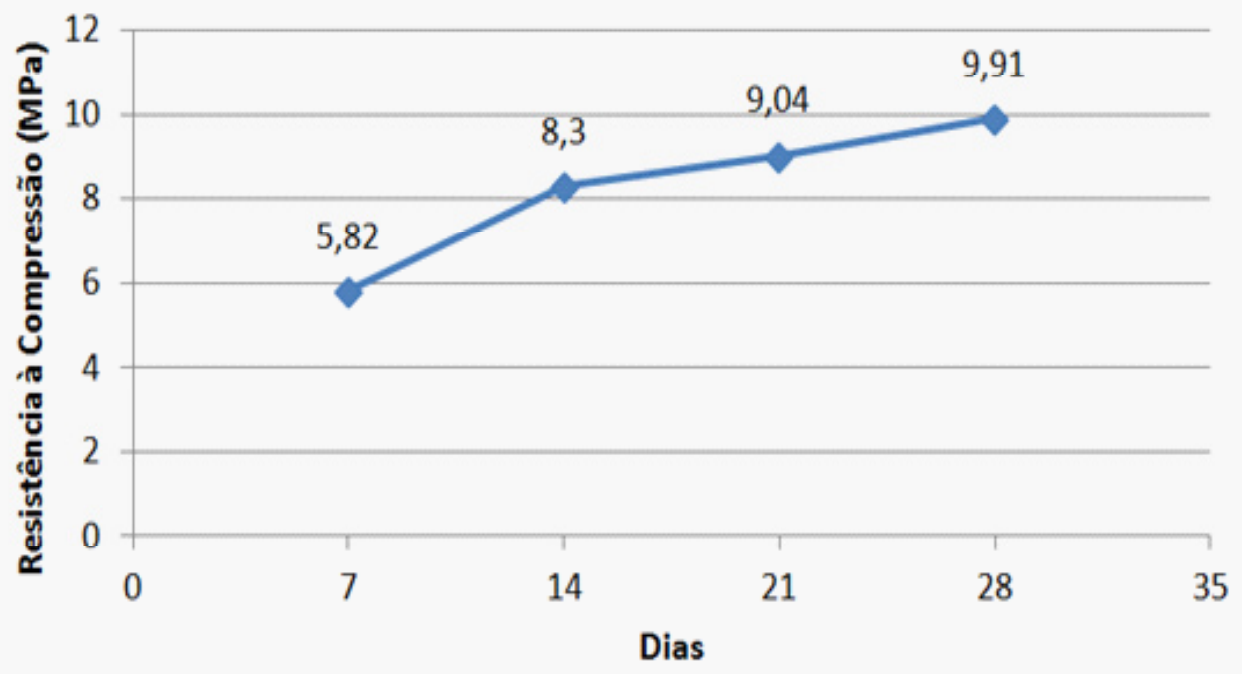

Figura 4: Gráfico das médias de valores obtidos para a respectiva idade de cura. 
para a deterioração do concreto, provocando assim a formação do gel expansivo que causa a diminuição da resistência ${ }^{3}$.

\section{Conclusões e disposições finais}

A partir dos resultados obtidos da análise de compressão, nota-se que o concreto desenvolvido conforme a metodologia mencionada, não atingiu a resistência prevista de $40 \mathrm{MPa}$ e não pode ser empregado para fins estruturais por obter a resistência a compressão inferior a $20 \mathrm{MPa}$ (NBR 8953, 2015). Entretanto, análises futuras são sugeridas, uma vez que a proporção (traço) dos componentes do concreto pode influenciar a resistência do concreto endurecido (Mehta, 2008).

Em contrapartida, a característica de baixa resistência pode ser aproveitada para aplicação em concretos não estruturais, como por exemplo concreto magro, chaminés, meio-fio, calçadas, artefatos de concreto, desde que atendam aos requisitos das normas vigentes.

Referindo-se ainda sobre a temática de pesquisas porvir, podem-se sugerir análises que identifiquem as propriedades químicas, térmicas e acústicas para que sejam aplicadas em outros ramos da engenharia civil.

Outra proposta para pesquisas futuras é destinar o RCD para análises e fabricação de argamassas, que segundo Levy (1997 como citado em Angulo, 2000), produziram-se argamassas com resíduos e obtiveram resistências superiores às convencionais.

\section{Referências}

Angulo, S. C. (2000). Variabilidade de agregados graúdos de resíduos de construção e demolição reciclados. (Tese de doutorado), Escola

Politécnica, Universidade de São Paulo, São Paulo, SP, Brasil.

Associação Brasileira De Normas Técnicas NBR 6118 (2003). Projeto de estruturas de concreto-Procedimento. Rio de Janeiro.

Associação Brasileira De Normas Técnicas NBR 5738 (2003). ConcretoProcedimento para modelagem e cura de corpos- de- prova. Rio de Janeiro.

Associação Brasileira De Normas Técnicas NBR 15116 (2004). Agregados reciclados de resíduos sólidos da construção civil-Utilização em pavimentação e preparo de concreto sem função estrutural. Rio de Janeiro.

Associação Brasileira De Normas Técnicas NBR 8953 (2015). Concreto para fins estruturais- Classificação pela massa específica, por grupos de resistência e consistência. Rio de Janeiro.

Associação Brasileira De Normas Técnicas NBR 12655 (2015). Concreto de cimento Portland- Preparo, controle, recebimento e aceitação- Procedimento. Rio de Janeiro.

Associação Brasileira Para Reciclagem De Resíduos Da Construção Civil. Recuperado em 01 de agosto de 2017, dehttps://abrecon.org.br/o-queeentulho/

Brasil, CONAMA n³07 (2002). Estabelece diretrizes, critérios e procedimentos para a gestão dos resíduos da construção civil. Brasília.
Corrêa, L. R. (2009). Sustentabilidade na construção civil. Dissertação de monografia, Universidade Federal de Minas Gerais, Belo Horizonte, MG, Brasil.

Cunha, J. C. S., Delgado, H. G. Jr., \& Lacerda, C. (2016). Traços de Concreto Sem Função Estrutural com Adição de Entulho. Cadernos UniFOA, 11(32), $35-45$.

Grubba, D. C. R. P. (2009). Estudo do comportamento mecânico de um agregado reciclado de concreto para utilização na construção rodoviária. Dissertação de doutorado, Universidade de São Paulo, São Paulo, SP, Brasil.

John V. M., 2001. Aproveitamento de resíduos sólidos como materiais de construção (Cap. 1, pp. 26- 45). Salvador: EDUFBA.

Lima, R. B. S., Silva, A. S. R., \& Costa, F. N. (n.d.) Reação álcali agregado e seus efeitos na construção de edifícios. Recuperado em 04

de agosto de 2017, de http://www.joinville.udesc.br/portal/professores/ carmeane/materiais/ART_020709.pdf

Mehta, P. K., \& Monteiro, P. .J. M. (2008). Concreto: microestrutura, propriedades dos materiais (3a ed.). São Paulo: Ibracon.

Reações Álcalis-Agregado Em Estruturas De Concreto. Recuperado em 04 de agosto de 2017,dehttp://www.ecivilnet.com/artigos/reacoes_alcalis agregado.htm? $=\mathrm{rea} \% \mathrm{C} 3 \% \mathrm{~A} 7 \% \mathrm{C} 3 \% \mathrm{~B} 5 \mathrm{es}+$ alcalis $\& \mathrm{x}=0 \& \mathrm{y}=0$.

Seminário Nacional Da Reciclagem De Resíduos Da Construção Civi E Demolição. (2015). Recuperado em 25 de julho de 2017, http://www. acquacon

com.br/seminariorcd/index.php

Vieira, G. L., Dal Molin, D. C., \& Lima, F. B. (2004). Resistência e durabilidade de concretos produzidos com agregados reciclados provenientes de resíduos de construção e demolição. Revista Engenharia Civil da Universidade do Minho, 19, 5-18. 